Navas Guzmán, Lidia.

Doctoranda UPV. Profesora titular, Universidad Laica Eloy Alfaro de Manabí, Facultad de

Comunicación, Grupo de Investigación en Comunicación, identidad y cultura.

Henríquez Coronel, Patricia.

PhD en Innovación educativa. Profesora titular, Universidad Laica Eloy Alfaro de Manabí, Facultad de Comunicación, Grupo de Investigación en Comunicación, identidad y cultura.

\title{
Estudio exploratorio para la gestión de plataformas culturales como medio educativo y de desarollo local para comunidades desfavorecidas; Ecuador.
}

\section{Exploratory study for the management of cultural platforms as a means of education and local development for disadvantaged communities; Ecuador.}

TIPO DE TRABAJO:

Comunicación.

PALABRAS CLAVE:

Arte Plataforma cultural Comunidad rural Ecuador.

KEY WORDS:

Art Cultural platform Rural community Ecuador.

RESUMEN.

Más allá de su función como experiencia estética, la expresión artística ha llegado a ser la vía idónea para generar proyectos participativos con la sociedad creando "redes de apoyo para reforzar el sentido de pertenencia a una comunidad y reajustar los sistemas de relaciones vitales a nivel familiar, grupal y social" (Abad, 2009).

Es por eso que, la investigación que se está llevando a cabo, pretende desarrollar proyectos artísticos capaces de generar un cambio social, de desarrollo local y educativo, a través de diferentes disciplinas artísticas para ser puestos en marcha y vinculados a una comunidad rural de la costa sur ecuatoriana: La Comuna Las Tunas.

En una primera etapa, la investigación se halla en fase de reconocimiento territorial. Esta comunicación describe por un lado, los lineamientos del proyecto de investigación para la creación de una plataforma de gestión cultural y por otro, la comunidad de intervención en cuestión y las prácticas artísticas que se están llevando a cabo dentro y fuera de las escuelas.

ABSTRACT.

Beyond its function as an aesthetic experience, artistic expression has become the ideal way to generate participatory projects with society by creating "support networks to strengthen the sense of belonging to a community and to readjust the systems of vital relationships at the family level, group and social" (Abad, 2009). 
That is why, the research that is being carried out, aims to develop artistic projects capable of generating social change, local development and education, through different artistic disciplines to be set up and linked to a rural community of the Ecuadorian south coast: The Las Tunas Commune.

In the first stage, the investigation is in the phase of territorial recognition. This communication describes, on the one hand, the guidelines of the research project for the creation of a cultural management platform and, on the other hand, the intervention community in question and the artistic practices that take place inside and outside the schools.

\section{CONTENIDO.}

\section{INTRODUCCIÓN.}

Nuestra experiencia como docente universitaria y residente en Ecuador, y la influencia, tanto personal como profesional, que está suponiendo nuestra convivencia con La Comuna Las Tunas ${ }^{1}$, genera una especial atención y responsabilidad social por las problemáticas encontradas. Es un lugar de escasos recursos, se encuentra en estado de vulnerabilidad social, económica y educativa pudiéndose observar que existe un índice elevado de jóvenes que abandonan sus estudios; por un lado para ayudar en el mantenimiento económico familiar y por otro, por el desinterés de una formación educativa. Se suma que es una zona explotada para el turismo temiéndose que sus paisajes, costumbres y modos de vida ancestrales desaparezcan.

El proyecto de investigación que se plantea, se centra en la generación de una plataforma perdurable que establezca nuevas relaciones y experiencias sociales entre artistas y La Comunidad. En esta primera fase investigativa, el nexo antropológico lleva al encuentro con sus influencias artísticas y raíces culturales que permiten observar los cambios llevados desde sus primeras manifestaciones hasta la actualidad analizando sus costumbres y modos de vida. Así se contextualiza el territorio y se adentra a la problemática a partir de entrevistas a morantes y representantes locales. Por otro lado, se identifican algunos proyectos sociales de acción artísitica participativa que están estrechamente vinculados con el lugar y sus habitantes. Una serie de entrevistas, desvelan cuáles han sido su forma de actuación y los resultados obtenidos.

En los años 70 la expresión de arte comunitario nace a partir de intentar a mejorar problemáticas sociales desde el arte (Garrido, 2009) llegando hoy en día, a ejecutarse proyectos ejemplares que se caracterizan por la inclusión social participativa, educativa y cultural dentro del contexto en el que se desarrollan. Garrido nos habla del concepto de arte comunitario en relación con el arte público asumiéndolos como una clase de acciones que buscan, más allá de un fin estético, una mejora social en un determinado contexto; el artista comisiona parte de sus funciones a una comunidad específica, de manera que la obra de arte se convierte en un proyecto de intervención social.

El concepto de inclusión social que López Fdz. Cao (2016, p. 210) define como "una compleja red de subalteridades que hacen que una persona, un grupo o una comunidad, quede fuera de aquellos derechos que habían sido diseñados para el bienestar humano en general". Lo cierto es, que estamos ante una problemática que persiste en el siglo XXI, y la exclusión o inclusión social, es un tema que en el mundo del arte, no se quiere dejar atrás. Ahora, los espacios expositivos aportan, además de conocimiento y belleza patrimonial, un cambio importante que López Fdz. Cao narra de "antropológico, educativo y social [...] para empoderar y trabajar con personas o colectivos en situación de vulnerabilidad" (p. 211).

White \& Rentschler (2005 citado en Nardone, 2011) reflexiona acerca del impacto del arte comunitario y apoya la idea de este autor de la necesidad de investigaciones que sostengan una metodología más exhaustiva en este tipo de prácticas. Halla las aportaciones de Matarasso (1997) en el que se examina más de 60 proyectos para dar a conocer la metodología de acción y evaluación para categorizarlas en diferentes aspectos: 1. desarrollo personal; basado en el cambio positivo de la capacidad del individuo, 2 . cohesión social consistente en la integración personal hacia otros grupos sociales, 3. empoderamiento comunitario, capacidad para involucrarse y desarrollar proyectos, 4. imagen local e identidad, forjar el sentido de pertenencia del lugar que habita, 5. imaginación y visión, exponer y dar uso de la creatividad para desarrollar cambios positivos, 6 salud y bienestar, sentirse realizado al formar parte proyectos a través del arte y la educación que generan beneficios a la comunidad.

\footnotetext{
${ }^{1}$ En la división política estatal, La Parroquia de Salango ubicada dentro del Canton Puerto López, esta conformada por diferentes recintos rurales entre los que conforman La Comuna Las Tunas: Puerto Rico, Las Tunas y Ayampe.
} 


\section{INVESTIGANDO SOBRE EL USO DE LA EXPRESIÓN ARTÍSTICA PARA EL DESARROLLO LOCAL Y EDUCATIVO.}

Esta investigación forma parte de la Tesis Doctoral aun en proceso titulada: Gestión de proyectos artísticos para el desarrollo local y educativo en comunidades rurales de Ecuador; Comuna Las Tunas, Manabí. El objetivo principal parte de la creación de una plataforma cultural generadora de proyectos de desarrollo local y educativo a través de las artes. Se basa en una metodología de acción participativa y se irán integrando artistas cuyos proyectos (de cualquier disciplina artística) se desarrollen conjuntamente con la comunidad. Adoptando la metodología descrita por Matarasso (1997) ya citado por Nardone (2011) anteriormente, donde los medios para la recopilación de información se basaron en entrevistas, grupos focales y en la observación participante, se incluye la documentación fotográfica y audiovisual del proceso de la Tesis con mayor hincapié en las propuestas artísticas.

Este trabajo se enmarca dentro de los estudios del arte como herramienta para el desarrollo local y educativo, las dimensiones de la expresión artística y el significado de resultados en las comunidades de escasos recursos visibilizando su identidad y realidad. El punto de partida es el análisis de las primeras actuaciones llevadas a cabo por este medio alcanzando las investigaciones desarrolladas de artistas contemporáneos que están aún explorando esta práctica comunitaria. Se apoya en los argumentos teóricos y metodológicos, y en los proyectos realizados exitosamente buscando nuevas experiencias artísticas que arrojen resultados positivos para la comunidad y la perdurabilidad de la plataforma cultural.

Parte la idea de que la educación es la base del desarrollo de una sociedad y los proyectos que se propongan en esta plataforma cultural, deben plantear la vinculación con las escuelas integrando a toda la comunidad en la búsqueda de medios para interpretar, fomentar y construir colectivamente significados para el desarrollo local y educativo, es decir, esta investigación debe participar y colaborar con las escuelas del lugar. No se pretende cambiar el currículo establecido por el Estado ecuatoriano (Ministerio de Educación, Currículo de Educación Cultural y Artística de Educación General Básica, 1997) pero sí acompañarlo desde una perspectiva extraescolar o como apoyo metodológico al maestro.

En Ecuador se están desarrollando proyectos artísticos comunitarios enfocados a los planteamientos interferidos en esta investigación: Colectivo Tranvía Cero (Almeida, 2012) muestra el poder de la experiencia artística para reflexionar sobre los valores socioculturales y políticos que integran, en este caso rincones donde apenas existen alternativas, de la ciudad de Quito. Arias (2013) plantea la educación artística para el desarrollo de América Latina en el uso de las Tics con el proyecto de llustratis 2.0 desarrollado en la Amazonía. Sin embargo, en la costa ecuatoriana apenas se visualizan proyectos similares a los encontrados en el resto del país. Una de las pretensiones de esta tesis, es dar mayor visibilidad de la diversidad cultural existente en Ecuador y aportar los beneficios de trabajar en colectividad a través del arte en la costa sur ecuatoriana.

\section{DIAGNÓSTICO DE LA REALIDAD ESTUDIADA: COMUNA LAS TUNAS.}

La Comuna Las Tunas es una comunidad rural perteneciente al Cantón de Puerto López, provincia de Manabí. Se ubica en el extremo suroeste de la costa ecuatoriana formando parte de la Ruta del Spondylus ${ }^{2}$. Debido a su situación geográfica (linda con el Parque Nacional Machalilla ${ }^{3}$ ) es una zona rica en recursos naturales con una gran extensión de bosque y playa. Muy visitada por turistas nacionales y extranjeros, se la ha considerado área turística protegida para salvaguardar y mantener su biodiversidad (Navas, L. Vera, J., 2016).

Guarda una fuerte tradición cultural y su restos arqueológicos explican el fenómeno espiritual que transmite. Las evidencias rescatadas de Salango, la comunidad vecina a la Comuna Las Tunas, muestra una gran riqueza cultural ancestral. Este pueblito nacido a las orillas del mar, fue testigo de los asentamientos costeros de seis culturas precolombinas que datan 5000 años de existencia: Valdivia, Machalilla, Chorrera, Bahía, Guancala y Manteña. Se han encontrado utensilios de cocina, herramientas de trabajo, vasijas, incluso piezas claves de escenarios para la realización de rituales públicos como entierros y ofrendas de artefactos. No solo consta como fuente de conocimiento en la arqueología ecuatoriana, también ha sido fuente de sabiduría para la cosmología e ideología. La decoración compuesta aparecida en sus vasijas representan la presencia en sus hogares de los difuntos humanos y la presencia de criaturas espirituales. "Estas criaturas, además, conformaban una fuerza nueva dentro del ambiente religioso del área, y señalan un cambio dramático en cuanto a la percepción de los poderes ocultos del cosmos y su relación con la sociedad humana." (Lunnis, 2013, parraf 26).

\footnotetext{
${ }^{2}$ Ruta del Spondylus. Es el nombre que se le da al recorrido geográfico de la costa pacífica ecuatoriana. El nombre de Spondylus viene dado por una concha que aparece en su océano y que fue utilizada como una pieza sagrada y venerada, símbolo de la riqueza de la cultura precolombina hasta elpunto de usarla como moneda de cambio.

${ }^{3}$ Parque Nacional Machalilla. Creada en 1979 y constituida como una de las primeras Áreas Protegida del Ecuador con una extensión de 41754 hectáreas terrestre de bosques secos y semisecos y 14430 hectáreas de ambiente marino.

http://areasprotegidas.ambiente.gob.ec/es/areas-protegidas/parque-nacional-machalilla Fecha de consulta, marzo 2017.
} 

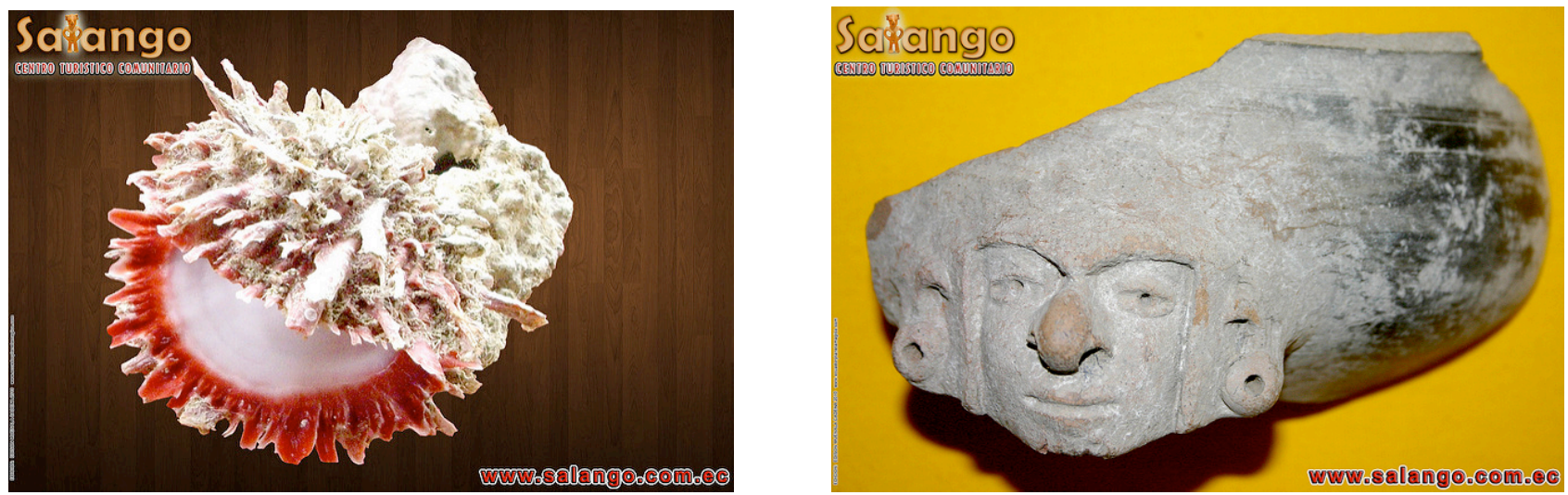

Figura 1. Concha Spondylus. Figura 2. Resto arqueológico de un cuenco decorado con rostro. Imágenes extraídas de www.salango.com.ec

Todas estas comunidades situadas sobre la línea costera han tenido la pesca como fuente principal de ingresos. Hoy en día, en Puerto López y Salango, aun se faena bajo los estándares de la pesca artesanal. Perdura la balsa manteña, símbolo de su tradición ancestral marina y la actividad comercial en la facilidad pesquera. Cada año se representada en Salango sus tradiciones culturales identitarias con el Festival de la Balsa Manteña (Bauer, 2010). Estos oficios tradicionales están sufriendo algunos cambios debido a la visión emprendora de "forasteros", nacionales y extranjeros, que eligieron al Cantón Puerto López por su gran potencial natural, el lugar idóneo para emprender negocios en el sector turístico.

Este nuevo emprendimiento económico que se esta desarrollando trae consigo consecuencias que afectan sobre todo a la pérdida de la identidad cultural, presente únicamente en los rasgos físicos caracterísiticos de sus ancestros (nariz aguileña, piel oscura, estatura baja, etc.). La mayoría de los moradores pasan a trabajar a dicho sector turístico a cambio del salario básico (alrededor de unos $\$ 360$ mensuales) y menos esfuerzo físico. Otra consecuencia es la de aquellos que dejan de darle vida a sus tierras comunales ${ }^{4}$ a cambio de su venta ${ }^{5}$ por un valor minoritario y terminar, en muchos casos, sirviendo en su propia tierra para quiénes le pagaron por ella. $Y$ otros pasan a formarse como guías turísticos especializados.

La mayoría pertenecen a una clase social baja y sus recursos económicos no alcanzan para mantener a una familia numerosa. El machismo existente hace de la mujer, fiel y servicial compañera, perfecta madre de familia y ama de casa, impidiéndole en la mayoría de casos, salir a trabajar fuera del hogar y donde el golpe aferra a otras tantas. Las niñas se embarazan a una temprana edad y los chicos abandon el colegio para mantener a su nueva familia. El alcohol o las drogas son el mejor refugio. Y la opción a una buena educación esta lejos de encontrarse o simplemente no hay interés por encontrarla.

La realidad de esta población exhibe el grado de vulnaveridad al que están expuestos. Tras la búsqueda de proyectos artísticos o culturales que se vinculen con La Comunidad, se encuentra la propuesta de Crisfe Fundación. Ellos se enfocan en mejorar la calidad de vida de comunidades ecuatorianas desfavorecidas a través de programas estratégicos fundamentados en tres ejes: eduación, emprendimiento y gestión social. En el área de educación, una de las estrategias metodológicas utilizadas parten del arte y la cultura. Jhonson Morantes, integrante de la Fundación destinado a trabajar en el Cantón de Puerto López habla sobre la metodología que usan y las experiencias obtenidas. Actualmente se encuentra trabajando con la escuelita del Recinto de Puerto Rico:

“[...] básicamente se trabaja con el acompañamiento al docente. Nuestra experiencia de trabajo se ha ido adaptando de acuerdo a las condiciones del medio. Los chicos adolecentes de 13 años en adelante les cuesta participar, ya están pensando en otras cosas y decidimos implantarlo para niños de 8 a 12 años, es decir trabajamos desde 4 to a 7 mo de básica. La metodología que utilizamos es para utilizarla sobre todo con la materia de lengua y literatura, dentro de la maya curricular con el permiso del Distrito de Educación y depende del maestro si quiere utilizarla en otras asignaturas. Por ejemplo para una indroducción dinámica, partimos de un cuento, trabajamos la estructura con los chicos y sacamos personajes, su época, la situación geográfica, etc. Después de todo esto le pedimos a los chicos comiencen a hacer su propio cuento con relación a su entorno, al medio en el que viven. Y luego a ese cuento le empezamos a hacer una canción, así mismo trabajamos la estructura de la canción con un ritmo y rima. Le ponemos una coreografía

\footnotetext{
${ }^{4}$ Ley de Comunas. La aprobación de esta Ley en 1937 otorga el reconocimiento a asociaciones sindicales y diferentes gremios para la protección de sus intereses "[...] fragmenta los territorios, incrementa las posibilidades de parcelación y venta, afianza el dominio de la propiedad privada, y favorece las estrategias familiares individuales, [...]". Para que cualquier Recinto se convirtiera en Comuna, de administración democrática y autogestionada, bastaba con un mínimo de 50 personas y la división de tierras de las "Grandes Comunidades Étnicas". (Álvarez, 2002, p27).

${ }^{5}$ Desde hace aproximadamente unos seis años, ha habido una fuerte demanda, tanto nacional como extranjera, por la compra de terrenos comunales para su explotación económica: reventa de tierras, construcciones hoteleras, viviendas, etc.
} 
y la bailamos. Entonces a ese cuento lo cogemos y lo pintamos [...] Finalmente hacemos una presentación teatral final para el pueblo en alguna sala de eventos o en las propias escuelas. Es increíble, como experiencia personal me he encontrado con niños que hoy en día son buenos chicos, no se han desviados, no alcohol, nada".
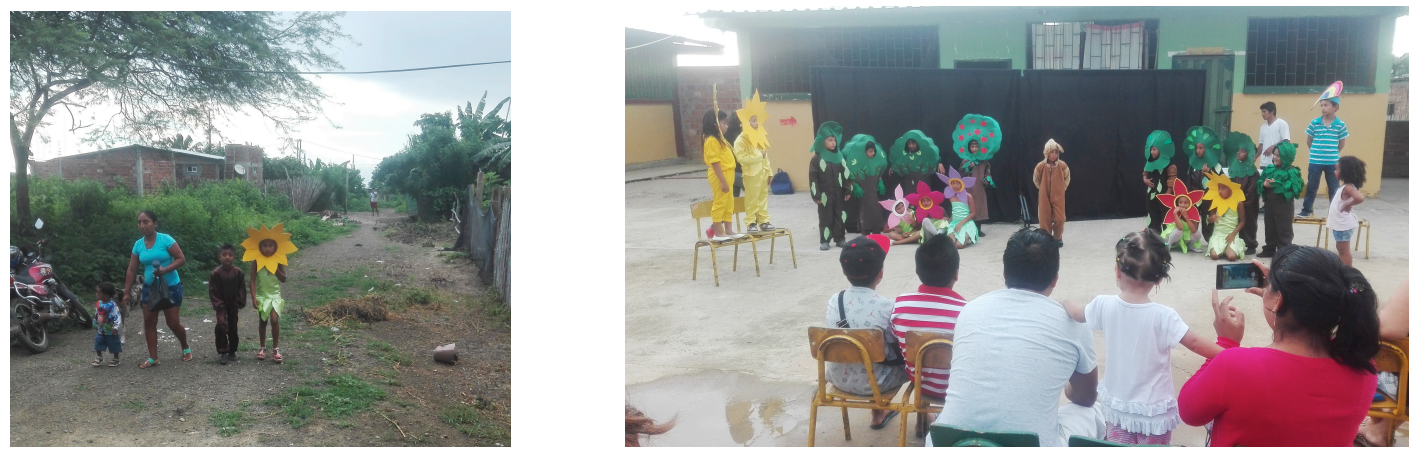

Figura 1 y 2. Presentación teatral de la Escuela de Machalilla con Crisfe Fundación, Cantón Puerto López. Imágenes originales de salida de campo.

Por otro lado, una residencia de artistas está funcionando en el Recinto de Ayampe desde el 2016, Truequé. Este espacio de creación y de laboratorio para artistas busca crear redes de encuentro con el objetivo principal de generar arte e intercambiar ideas. Las actividades que se realizan van desde talleres de autoformación hasta jornadas reflexias y de experimentación. Cada artista proporciona conocimiento según su disciplina y al final de cada encuentro, tienen una pequeña muestra con la comunidad. En el 2016, colaboraron con un grupo de 15 niños del Reciento Las Tunas con un taller de fotoperformance, pintura y música. Tras eso se realizó una acción de espacio público y la creación de un mural donde los mismos chicos participaron. Este año, consideraron su espacio de residencia como su propia comunidad tratándolo más bien como un laboratorio experimental y considerando inoportuno hacer una acción en la comunidad sin una investigación previa adecuada. Pese a ello, hubieron algunos artistas residentes que encontraron la forma de actuar con los habitantes del lugar con un taller en forma de fiesta, una fiesta para las mamás de Ayampe.
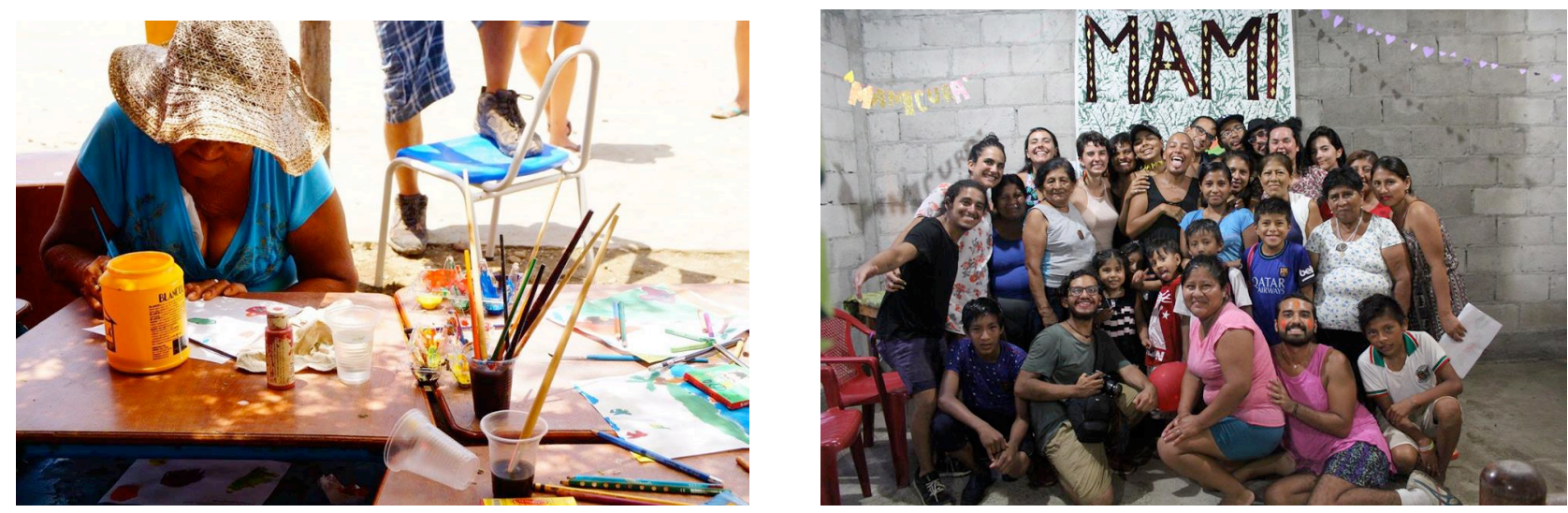

Figura 1. Encuentro con la comunidad de las Tunas. Truequé 2016 figura 2. Encuentro con la comunidad de Ayampe. Truequé 2017. Imágenes otorgadas por Stephano Espinoza, creador de Truequé.

\section{CONCLUSIONES.}

Son muchas las investigaciones realizadas en torno al desarrollo local y educativo a través del arte. Garrido (2010) cuenta que la educación artística comunitaria explora el nexo con la vida a través de la experiencia obtenida en proyectos basados en la realidad de su cotidianidad enfocándose en el "compromiso social y una idea del poder transformativo y emancipatorio de la educación"(p.110). Abad (2009) contempla positivamente el planteamiento de las artes en las escuelas de carácter social y cultural y nombra el programa internacional de MUS-E que sienta sus bases en proyectos enfocados al beneficio de actitudes y prácticas que siembren "una conciencia crítica frente a los mecanismos de exclusión social, y convertirse, a la larga, en un proceso consciente de crecimiento individual y colectivo" (p. 19). 
La idea de realizar proyectos comunitarios dentro un contexto social vulnerable es un reto difícil pero no imposible. Existen importantes líneas de acción con las que anexarse y comezar a formar parte de una red de colaboración con La Comunidad junto con Crisfe Fundación y Residencia Truequé. Con la primera citada, a pesar de la buena predisposición de los integrantes, no disponen de recursos humanos suficientes para abarcar a todas las comunidades. Además la metodología utilizada funciona correctamente para niños pero quedan obsoletas para los jóvenes adolescentes. Con la integración de personas especializadas en diferentes disciplinas artísticas pudiera complementarse nuevos talleres enfocados a las problemáticas específicas de cada comunidad. Las relaciones establecidas con la Residencia Truequé, dará pie al contacto con artistas que quieran emprender proyectos comunitarios de manera conjunta.

Tras esta primera fase investigativa, la viabilidad del proyecto tiende a ser favorable para actuar en los Recintos de la Comuna Las Tunas. Se evidencia la necesidad de emprender proyectos que establezcan nuevas estrategias didácticas que aumenten el grado de interés en la formación educativa de los jóvenes y en el desarrollo local de las comunidades. Una vez terminada esta etapa cuyos resultados otorguen información suficiente para el proceso de actuación, se dará paso a la etapa de programación de los proyectos de desarrollo local y educativo a implementar en la zona. Se realizará un estudio previo de cuáles serán los medios idóneos para, en primer lugar, establecer contacto con artistas que quieran participar en el proyecto y por ende desarrollar sus propuestas, después promover el diseño de las propuestas conjuntas entre el artista y La Comunidad y por último, implementarlas. Con la búsqueda de financiación pública o privada, se lanzarán convocatorias a artistas que deseen formar parte de esta plataforma cultural. Ésta (aun sin nombre) pretende ir retroalimentándose para generar proyectos nuevos y seguir en constante movimiento colaborativo.

\section{FUENTES REFERENCIALES.}

ABAD, Javier. Usos y funciones de las artes en la educación y el desarrollo humano. Educación artística, cultura y ciudadanía, 2009, p. $17-23$.

ALMEIDA, Pablo X., et al. Arte y comunidad: Espacios de transformación. ARQ (Santiago), 2012, no 81, p. 62-66.

ÁLVAREZ, Silvia G. Etnicidades en la costa ecuatoriana. Editorial Abya Yala, 2002.

ARIAS SÁNCHEZ, Melania. Educación artística y nuevas tecnologías vinculadas a una educación para el desarrollo en América Latina. Proyecto Illustratis 2.0. 2013. Tesis Doctoral. Universidad Complutense de Madrid.

BAUER, Daniel Eric. Tradición e identidad cultural: Expresiones Colectivas en la Costa Ecuatoriana. Revista de Antropología Experimental, 2010, vol. 10, p. 183-194.

CAO, Marián López Fdz. Indicadores sobre prácticas artísticas comunitarias: algunas reflexiones. Arteterapia. Papeles de arteterapia y educación artística para la inclusión social, 2016, vol. 10, p. 209-234.

Currículo de Educación Cultural y Artística de Educación General Básica. Ministerio de Educación, 1997. https://educacion.gob.ec/wpcontent/uploads/downloads/2016/08/ECA-completo.pdf Fecha de consulta octubre 2016

PALACIOS GARRIDO, Alfredo. Educación artística comunitaria en Finlandia: entrevista a Timo Jokela. 2010.

GARRIDO, Alfredo Palacios. El arte comunitario: origen y evolución de las prácticas artísticas colaborativas/Community art: origin and evolution of collaborative artistic practices. Arteterapia, 2009, vol. 4, p. 197-211.

LUNNISS, Richard. Rescatando el patrimonio cultural ecuatoriano: el centro ceremonial precolombino de salango. Arqueología ecuatoriana, 2013. https://www.arqueo-ecuatoriana.ec/es/home/editorial Fecha de consulta, marzo 2017

NARDONE, Mariana. Arte comunitario: criterios para su definición. Miríada: Investigación en Ciencias Sociales, 2011, vol. 3, no 6, p. pp. 47-91.

NAVAS, Lidia, VERA, Jenny. Reflexiones reflexiones sobre las áreas turísticas protegidas. caso de estudio puerto lópez: ilusión y realidad en proceso. VII Congreso Latinoamericano de la Asociación Mundial para la Investigación en Opinión Pública (World Association for Public Opinion Research, WAPOR), 2016. Monterrey, México. Policopiado.

Parque Nacional Machalilla. http://areasprotegidas.ambiente.gob.ec/es/areas-protegidas/parque-nacional-machalilla Fecha de consulta, marzo 2017. 